\title{
Vertical distribution and settling pool of Chromium in the bay mouth of Jiaozhou Bay
}

\author{
Dongfang Yang ${ }^{1,2,3, a}$, Fengyou Wang ${ }^{1,2, b}$, Zhaohui Sun ${ }^{1,2}$, Xiaoli Zhao ${ }^{1,2}$ and \\ Sixi Zhu ${ }^{1,2}$
}

${ }^{1}$ Research Center for Karst Wetland Ecology, Guizhou Minzu University, Guiyang 550025, China;

${ }^{2}$ College of Chemistry and Environmental Science, Guizhou Minzu University, Guiyang 550025, China;

${ }^{3}$ North China Sea Environmental Monitoring Center, SOA, Qingdao 266033, China

adfyang_dfyang@126.com; ${ }^{\mathrm{b} C}$ Corresponding author fywang@163.com.cn

Keywords: Chromiun, Vertical distribution, Seasonal variation, Settling process, Jiaozhou Bay.

\begin{abstract}
This paper analyzed the seasonal variation, horizontal distribution, vertical distribution and variation range of Chromium (Cr) in the bay mouth of Jiaozhou Bay based on investigation data in 1983. Results showed that Cr contents in different seasons in both surface and bottom waters were in order of spring < summer $<$ autumn. The input of $\mathrm{Cr}$ from stream flow discharge in determined the change of the variation of Cr content in both surface and bottom waters. From May, September and October, as time passed by, Cr contents and horizontal distributions in bottom waters were tending to be consistent with that in surface waters. Moreover, there was always a big high Cr content region in bottom waters in the bay mouth in different seasons.
\end{abstract}

\section{Introduction}

Cr could be brought into water by various pathways, and was transported to the ocean finally [1-4]. There were a lot of suspended particulate matters in sea waters, and Cr was absorbed to the colloid in the surfaces of suspended particulate matters, and was settling to the sea bottom continually under the effects of gravitational force and hydraulic power [2]. Hence, the vertical distribution and variation of $\mathrm{Cr}$ in marine waters was worth attention. This paper analyzed the seasonal variation, horizontal distribution, vertical distribution and variation range of Chromium (Cr) in the bay mouth of Jiaozhou Bay. Based on investigation data on $\mathrm{Cr}$ in surface and bottom waters in Jiaozhou Bay in 1983, the aim of this paper was to analyze the seasonal variation, horizontal distribution, vertical distribution and variation range of $\mathrm{Cr}$, and to provide basis to both scientific research and pollution control.

\section{Study area and data source}

Jiaozhou Bay $\left(35^{\circ} 55^{\prime}-36^{\circ} 18^{\prime} \mathrm{N}, 120^{\circ} 04^{\prime}-120^{\circ} 23^{\prime} \mathrm{E}\right)$ is located in Shandong Province, eastern China (Fig. 1). This bay is a semi-closed bay, whose total area, width of bay mouth, and average water depth are $446 \mathrm{~km}^{2}, 2.5 \mathrm{~km}$, and $7 \mathrm{~m}$, respectively. Cities of Qingdao, Jiaozhou and Jiaonan are located in the east, north and west of the bay. The bay mouth is located in the south of the bay, and is connected with the Yellow Sea. This bay has more than ten inflow rivers, such as Dagu River, Loushan River, Licun River and Haibo River, whose runoff are strongly determined by rainfall-runoff, and are showing significant seasonal features [5-6].

The data was provided by North China Sea Environmental Monitoring Center, State Ocean Administration. The investigation on $\mathrm{Cr}$ in surface and bottom waters at 5 sampling sites in Jiaozhou Bay was carried on in May, September and October 1983. The measurement of $\mathrm{Pb}$ was following by Chinese Specification for Marine Monitoring [7]. 


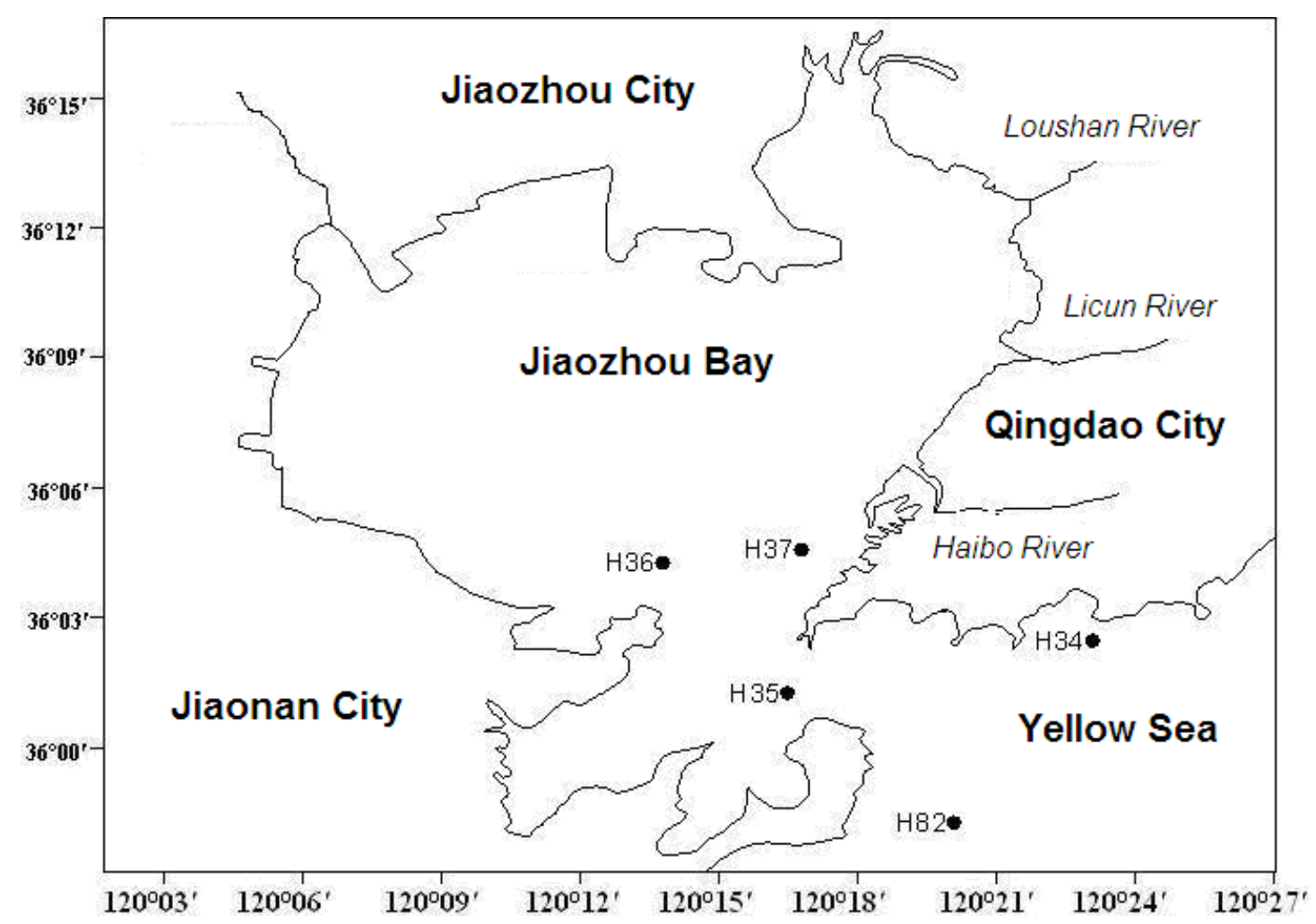

Fig. 1 Geographic location and sampling sites in Jiaozhou Bay

\section{Seasonal variation and horizontal distribution}

Cr contents in surface waters in May, September and October 1983 were $0.13-0.65 \mu \mathrm{g} \mathrm{L}^{-1}$, $0.70-1.17 \mu \mathrm{g} \mathrm{L} \mathrm{L}^{-1}$ and $0.44-1.56 \mu \mathrm{g} \mathrm{L}{ }^{-1}$, while for bottom waters were $0.11-1.08 \mu \mathrm{g} \mathrm{L}^{-1}, 0.46-1.17$ $\mu \mathrm{g} \mathrm{L}^{-1}$ and $0.63-1.58 \mu \mathrm{g} \mathrm{\textrm {L } ^ { - 1 }}$, respectively. Cr contents in different seasons in both surface and bottom waters were in order of spring $<$ summer $<$ autumn. The higher $\mathrm{Cr}$ contents in surface water the higher $\mathrm{Cr}$ contents in bottom waters, that was $\mathrm{Cr}$ contents in bottom waters were determined by which in surface waters. The seasonal variations of $\mathrm{Cr}$ contents in both surface and bottom waters indicated that $\mathrm{Cr}$ contents were increasing with time within year. For horizontal distribution, $\mathrm{Cr}$ contents in both surface and bottom waters in different seasons were showing same trends that were decreasing gradiently from Site H37 to H35. It could be concluded that Cr contents and horizontal distributions in bottom waters were tending to be consistent with that in surface waters. This phenomenon was the result of the vertical water body effect [8].

\section{Settling process and the mechanism}

The variation and distribution of $\mathrm{Cr}$ in waters were results of the vertical water body effect [8]. Cr could be absorbed to marine guidance phytoplankton and suspended particulate matters [9]. This feature could impact the distributions of $\mathrm{Cr}$ in waters strongly. The growth and reproduction of marine organism increasing from summer [6], resulting in a lot of colloid. Hence, a large amount of Cr could be absorbed to these matters, and were settling to the sea bottom continually by means of gravitational force and hydrodynamic force [2].

There were many evidences to support the influences of vertical water body effect on the distribution of $\mathrm{Cr}$ in waters. At time scale, $\mathrm{Cr}$ contents in different seasons in both surface and bottom waters were in order of spring < summer < autumn, and the Cr contents in surface water were closed to that in bottom waters. The reason was that $\mathrm{Cr}$ was settling to the bottom waters under the horizontal water body effect, and was accumulating with time within year continually, leading to the consistency of $\mathrm{Cr}$ contents in different season. By the same way, the horizontal distributions of $\mathrm{Cr}$ contents in both surface and bottom waters were tend to be similar. 
In May and September, Cr contents in surface waters were higher than in bottom waters in waters inside the bay mouth and the waters in the south outside the bay mouth, while inverse phenomenon were occurred in the northeast of the bay mouth inside the bay. In October, $\mathrm{Cr}$ contents in surface waters were higher than in bottom waters in waters inside the bay, while inverse phenomenon were occurred in the bay mouth and the waters in the outside the bay mouth. These distributions indicated that the high $\mathrm{Cr}$ content region was transferred to the bay mouth and outside the bay mouth.

In generally, seeing from the horizontal distribution, $\mathrm{Cr}$ contents in surface waters were decreasing from the northeast to the southwest. Meanwhile, $\mathrm{Cr}$ was continuously settling to the bottom waters under the horizontal water body effect. Hence, high values of Cr were moved to the bottom water in the bay mouth and outside the bay mouth, and a high Cr value region in bottom waters were finally formed with time within year.

\section{Conclusion}

Cr contents in different seasons in both surface and bottom waters were in order of spring < summer < autumn. Cr contents and horizontal distributions in bottom waters were tending to be consistent with that in surface waters under the influences of horizontal water body effect.

Cr contents in surface waters were decreasing from the northeast to the southwest. Meanwhile, Cr was continuously settling to the bottom waters under the horizontal water body effect. Hence, high values of $\mathrm{Cr}$ were moved to the bottom water in the bay mouth and outside the bay mouth, and a high $\mathrm{Cr}$ value region in bottom waters were finally formed with time within year.

\section{Acknowledgement}

This research was sponsored by Doctoral Degree Construction Library of Guizhou Nationalities University, Education Ministry's New Century Excellent Talents Supporting Plan (NCET-12-0659), Project of Outstanding Technological Educators of Governor of Guizhou ([2012]71), Project of Low Carbon Technology Plan of Guiyang (2012205]), Project of Science and Technology Foundation of Guiyang (LKM[2012]05), Special Research Projects of High Level Talents of Guizhou Province (TZJF-2011- 44), and Research Projects of Guizhou Nationalities University ([2014]02).

\section{References}

[1] Yang DF, Gao ZH, Sun JY, et al.: Coastal Engineering, Vol. 27 (2008): 48-53. (in Chinese with English abstract)

[2] Yang DF, Wang FY, He HZ, et al.: Applied Mechanics and Materials, Vols. 675-677 (2014): 329-331.

[3] Chen Y, Yu QH, Li TJ, et al.: Applied Mechanics and Materials Vols. 644-650 (2014): 5329-5332.

[4] Yang DF, Zhu SX, Wang FY, et al.: 2014 IEEE workshop on advanced research and technology industry applications. Part D (2014): 1018-1020.

[5] Yang DF, Chen Y, Gao ZH, et al.: Chinese Journal of Oceanology Limnoogy, Vil. 23(2005): 72-90.

[6] Yang DF, Wang F, Gao ZH, et al.: Maine Science, Vol. 28(2004): 71-74. (in Chinese with English abstract)

[7] State Ocean Administration. The specification for marine monitoring ( HY003.4-91): Beijing, Ocean Precess, (1991). (in Chinese)

[8] Yang DF, Wang FY, He HZ, et al.: Proceedings of the 2015 international symposium on computers and informatics, (2015): 2655-2660.

[9] Wang ZL and Zhong YL: China Feed, Vol. 22 (1990):16-17. (in Chinese with English abstract) 